\title{
Extrapolation of Hepatic Concentrations of Industrial Chemicals Using Pharmacokinetic Models to Predict Hepatotoxicity
}

\author{
Hiroshi Yamazaki and Yusuke Kamiya \\ Laboratory of Drug Metabolism and Pharmacokinetics, Showa Pharmaceutical University, Tokyo, Japan
}

\begin{abstract}
In this review, we describe the absorption rates (Caco-2 cell permeability) and hepatic/plasma pharmacokinetics of 53 diverse chemicals estimated by modeling virtual oral administration in rats. To ensure that a broad range of chemical structures is present among the selected substances, the properties described by 196 chemical descriptors in a chemoinformatics tool were calculated for 50,000 randomly selected molecules in the original chemical space. To allow visualization, the resulting chemical space was projected onto a two-dimensional plane using generative topographic mapping. The calculated absorbance rates of the chemicals based on cell permeability studies were found to be inversely correlated to the no-observed-effect levels for hepatoxicity after oral administration, as obtained from the Hazard Evaluation Support System Integrated Platform in Japan $(r=-0.88, p<$ $0.01, \mathrm{n}=27$ ). The maximum plasma concentrations and the areas under the concentration-time curves (AUC) of a varied selection of chemicals were estimated using two different methods: simple one-compartment models (i.e., high-throughput toxicokinetic models) and simplified physiologically based pharmacokinetic (PBPK) modeling consisting of chemical receptor (gut), metabolizing (liver), and central (main) compartments. The results obtained from the two methods were consistent. Although the maximum concentrations and AUC values of the 53 chemicals roughly correlated in the liver and plasma, inconsistencies were apparent between empirically measured concentrations and the PBPK-modeled levels. The lowest-observed-effect levels and the virtual hepatic AUC values obtained using PBPK models were inversely correlated $(r=-0.78, p<0.05, \mathrm{n}=7)$. The present simplified PBPK models could estimate the relationships between hepatic/plasma concentrations and oral doses of general chemicals using both forward and reverse dosimetry. These methods are therefore valuable for estimating hepatotoxicity.
\end{abstract}

Key words: PBPK modeling, Caco-2 permeability, Hepatotoxicity, No-observed-effect level, Lowest-observedeffect level

\section{INTRODUCTION}

There is a wide variety of human-made chemicals in the environment. Organic compounds originating from myriad natural processes and industrial sources (1) are also

Correspondence to: Hiroshi Yamazaki, Laboratory of Drug Metabolism and Pharmacokinetics, Showa Pharmaceutical University, 3-3165 Higashi-tamagawa Gakuen, Machida, Tokyo 194-8543, Japan

E-mail: hyamazak@ac.shoyaku.ac.jp

This is an Open-Access article distributed under the terms of the Creative Commons Attribution Non-Commercial License (http:// creativecommons.org/licenses/by-nc/3.0) which permits unrestricted non-commercial use, distribution, and reproduction in any medium, provided the original work is properly cited. ubiquitous in the human environment. Because long-term exposure to some volatile organic compounds may increase the risk of cancer or birth defects, estimation of the exposures to such compounds is a research area that can have a significant positive impact on human health (2). Estimation of health risks due to chemical substances has historically followed guidelines on investigatory studies with experimental animals. The general toxicities of industrial chemicals have been extensively investigated by administering repeated oral doses of the chemicals to rodents. Nonetheless, in general, repeated-dose toxicity studies for many chemicals may require significant cost and time. For animal welfare, the current movement has been focused on developing alternative methods such as in vitro studies or in vitro studies mimmicking on in vivo studies. 
Recently developed high-throughput in vitro screening assays combined with in silico computational models might provide suitable alternative methods to conventional animal testing. However, the pharmacokinetics and/or toxicokinetics (including intestinal absorption) of industrial chemicals are not generally considered when evaluating their toxicological potential. Although extensive toxicity databases have been set up worldwide, only a limited numbers of industrial chemicals possess adequate in vivo toxicokinetic data related to pharmacokinetic parameters, such as absorption rates, for assessing potential hazards in humans (3). This fact highlights the urgent and significant need to develop more efficient and informative tools to determine toxicity.

To interpret toxicity data obtained from high-throughput in vitro screening, scientists at the United States regulatory authorities have recommended the inclusion of both dosimetry and exposure data supported by complex multicompartment pharmacokinetic models using full-scale physiologically based pharmacokinetic (PBPK) modeling $(4,5)$. Furthermore, recent studies have proposed extrapolation of in vitro toxicokinetic screening data to predict in vivo toxicokinetics based on chemical structure-based properties $(6,7)$. Against this background, our research group established a simplified systematic PBPK modeling with input parameters derived from in vitro and in vivo data and the literature $(8,9)$. Because of the utility and simplicity, these models could also be used by the regulatory authorities and the industrial researchers for risk assessment.

A five-year project has started in April 2017, sponsored by the Ministry of Economy and Trade Industry in Japan. The aim is to develop a high-accuracy in silico hazard prediction system based on toxicity mechanism using accumulated in vivo data over the past 40 years under the Chemical Substance Control Law and the results of in vitro studies in toxicology, along with artificial intelligence technology and human expertise (AI-based Substance Hazard Integrated Prediction System, https://ai-ships.net/en/ project.html). In this review, the absorption rates (Caco-2 cell permeability) and estimated plasma/hepatic pharmacokinetics of a variety of chemicals are evaluated as a part of this national project. The pharmacokinetic parameters were estimated using two approaches to model different chemicals orally administered to rats. The models made use of the reported or experimentally determined plasma pharmacokinetics data. If a successful method could be established to derive the in vivo absorption parameters of general chemicals from the measured in vitro permeability values, it would be of great benefit. Chemical risk assessment involves the prediction of hepatotoxicity, and the simplified PBPK models used here could predict the hepatic as well as the plasma concentrations of drugs and other chemicals after oral ingestion using both forward and reverse dosimetry.

\section{ORAL ABSORPTION OF CHEMICALS AND THEIR HEPATOTOXICITY}

The in vitro permeability assay is an established method in pharmaceutical research and is based on human models that use Caco- 2 colon cancer cell line to estimate the oral absorption of drugs and other substances (10-14). However, little information is available on the absorbability of industrial chemicals through the mucosa and/or gastrointestinal absorption, which is a necessary step before such chemicals can exert their toxicological potential.

The procedures used for preparing in vitro monolayers of human intestinal Caco-2 cells have been described previously (15). For experimental use, Caco-2 cells were seeded on permeable polycarbonate membranes at a density of $1.0 \times 10^{5}$ cells $/ \mathrm{cm}^{2}$ and were cultured for 3-4 weeks. The apparent permeability coefficients $\left(P_{\text {app }}, \mathrm{nm} / \mathrm{s}\right)$ for time-dependent in vitro absorption from the apical side of the Caco-2 monolayer [10 mM 2-morpholinoethanesulfonic acid monohydrate $(\mathrm{pH} \mathrm{6.0)]} \mathrm{to} \mathrm{the} \mathrm{basal} \mathrm{side} \mathrm{of} \mathrm{the}$ Caco-2 monolayer [10 mM 4-(2-hydroxyethyl)-1-piperazineethanesulfonic acid ( $\mathrm{pH}$ 7.4)] were calculated as described previously (15) (Fig. 1).

To investigate the relevance of $\mathrm{pH}$-dependent Caco-2 monolayer assays in the in vivo absorption rate, the relationship was examined between the measured $\log P_{\text {app }}$ values for the drugs and their reported absorbabilities (fraction absorbed, $F_{\mathrm{a}}$ ) in humans. To ensure that the substances analyzed exhibited a diversity of chemical structures, the structures defined by 196 chemical descriptors in a chemoinformatics tool were calculated for 50,000 randomly generated molecules in the original chemical space (15). To allow visualization, the resulting chemical space underwent projection onto a two-dimensional plane using generative topographic mapping (Fig. 2). In this figure, closer plots in the chemical space could indicate more similarity in the chemical properties. A wide range of apparent permeability coefficients $\left(P_{\text {app }}\right)$ (approximately $10-1,000 \mathrm{~nm} / \mathrm{s}$ )

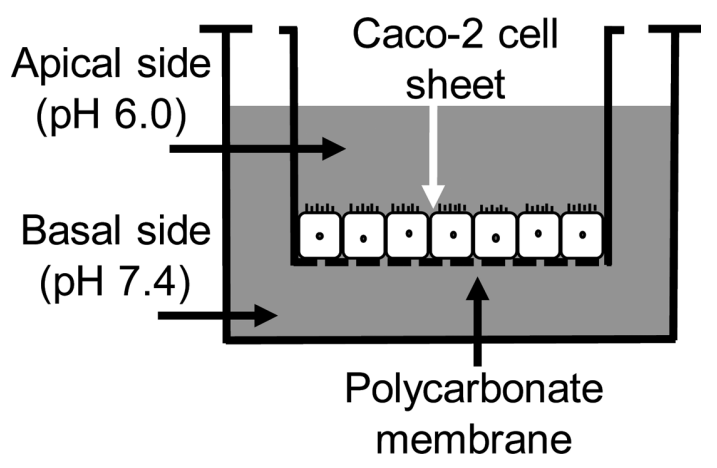

Fig. 1. Apparatus for intestinal epithelial permeability testing. The Caco-2 cell monolayer system was used for a variety of general chemicals. 


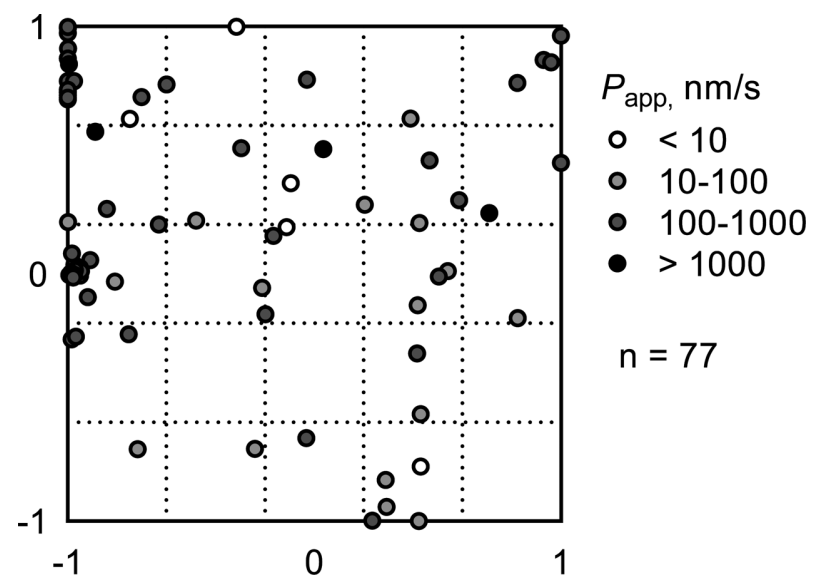

Fig. 2. Coordinate values in a two-dimensional plane illustrating a variety of chemical structures. The density of the circles indicates apparent permeability values of the chemicals across an intestinal epithelial cell monolayer.

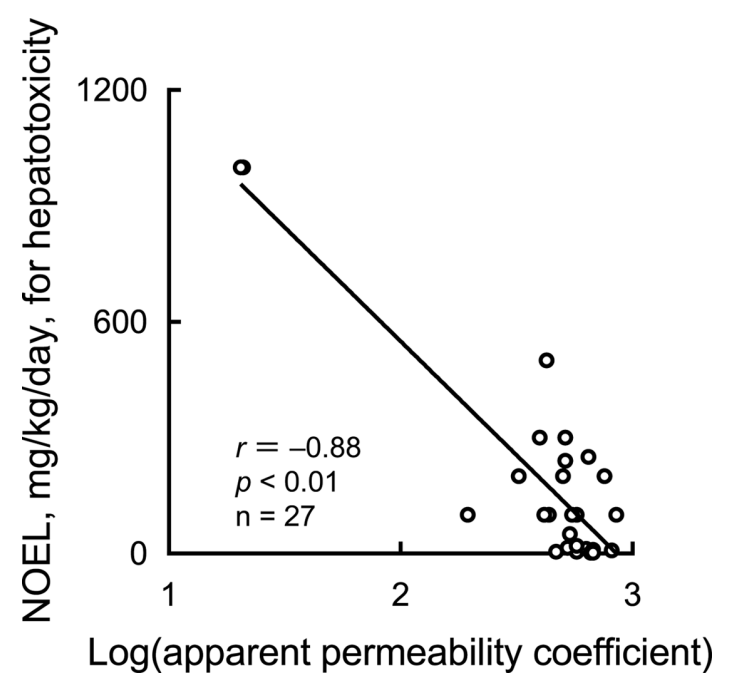

Fig. 3. The inverse relationship between hepatic NOEL values of the industrial chemicals reported in a rat database and the apparent permeability data measured using Caco-2 permeability assays.

across human intestinal epithelial Caco-2 cell monolayers was obtained for a diverse range of drugs/industrial chemicals. There was no evident relationship between the apparent permeability coefficients and the location on the chemical space represented by the two-dimensional plane in this study. Under the present conditions, the oral administration no-observed-effect levels (NOEL) given in the Hazard Evaluation Support System Integrated Platform (HESS) in Japan (16) and the chemical absorbance rates obtained from in vitro cell permeability data were found to be inversely correlated $(r=-0.88, p<0.01, \mathrm{n}=27$, Fig. 3).
(A)

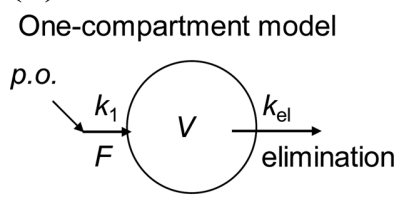

(B)

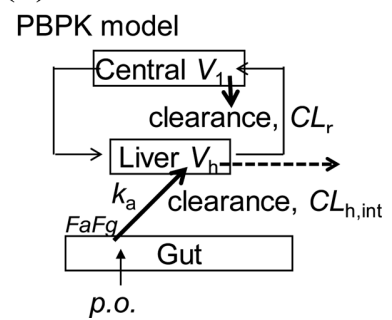

Fig. 4. Schematic representations of one-compartment (A) and PBPK (B) models to simulate virtual oral administrations of the chemicals. $F, F_{\mathrm{a}}$, and $F_{\mathrm{g}}$ : bioavailability, $k_{1}$, and $k_{\mathrm{a}}$ : absorption constants, $V, V_{1}$, and $V_{\mathrm{h}}$ : volumes of distribution, $k_{\mathrm{e}}:$ elimination constant, and $C L_{\mathrm{h}}$ and $C L_{\mathrm{r}}$ : clearances.

\section{HEPATIC CONCENTRATIONS OF CHEMICALS AND THEIR TOXICITIES}

The current study employed two modeling systems, the simple one-compartment model (Fig. 4A) that was recently recommended by US authorities as a high-throughput toxicokinetic screening tool, and a simplified PBPK model (Fig. 4B) made up of chemical receptor (gut), metabolizing (liver), and central (main) compartments. Examples of the plasma concentration curves of individual general chemicals estimated by the two models after virtual oral doses were reported previously $(8,17-28)$.

The simplified PBPK models were established as previously described $(9,15)$. For some chemicals, a peripheral compartment was used in addition to the central compartment. The general procedure for PBPK modeling is as follows: the octanol-water partition coefficient $(\log P)$ and the plasma unbound fraction $\left(f_{\mathrm{u}, \mathrm{p}}\right)$ of the general chemicals were estimated in silico using Chemdraw and the Simcyp simulator (29). The blood-to-plasma concentration ratio $\left(R_{\mathrm{b}}\right)$ and the liver-to-plasma concentration ratio $\left(K_{\mathrm{p}, \mathrm{h}}\right)$ were calculated from $f_{\mathrm{u}, \mathrm{p}}$ and $\log P$ values (30):

$$
K_{\mathrm{p}, \mathrm{h}}=\frac{0.02289 \cdot P+0.72621}{0.00396 \cdot P+0.960581} \times \frac{1+f_{\mathrm{u}, \mathrm{p}}}{2}
$$

The physiological values, such as the hepatic blood flow rate $\left(Q_{\mathrm{h}}\right)$ in rats $(0.853 \mathrm{~L} / \mathrm{h})$ were obtained from the literature (31). The volume of the systemic circulation $\left(V_{1}\right)$, the absorption rate constant $\left(k_{\mathrm{a}}\right)$, and the in vivo hepatic intrinsic clearance $\left(C L_{\mathrm{h}, \text { int }}\right)$ were evaluated using nonlinear regression analysis fitting techniques, as described previously (15). The renal clearance $\left(C L_{\mathrm{r}}\right)$ was set at a minimum value as compared to the hepatic clearance $\left(C L_{\mathrm{h}}\right)$. Finally, to perform modeling, the following system of differential equations (8) was solved:

$$
\frac{d X_{\mathrm{g}}}{d t}=-k_{\mathrm{a}} \cdot X_{\mathrm{g}} \text { when at } t=0, X_{\mathrm{g}}(0)=F_{\mathrm{a}} \cdot F_{\mathrm{g}} \cdot \text { dose }
$$




$$
\begin{aligned}
& V_{\mathrm{h}} \frac{d C_{\mathrm{h}}}{d t}=Q_{\mathrm{h}} \cdot C_{\mathrm{b}}-\frac{Q_{\mathrm{h}} \cdot C_{\mathrm{h}} \cdot R_{\mathrm{b}}}{K_{\mathrm{p}, \mathrm{h}}} \\
& \quad+k_{\mathrm{a}} \cdot X_{\mathrm{g}}-C L_{\mathrm{h}, \text { int }} \cdot \frac{C_{\mathrm{h}}}{K_{\mathrm{p}, \mathrm{h}}} \cdot f_{\mathrm{u}, \mathrm{p}} \\
& V_{1} \frac{d C_{\mathrm{b}}}{d t}=-Q_{\mathrm{h}} \cdot C_{\mathrm{b}}+\frac{Q_{\mathrm{h}} \cdot C_{\mathrm{h}} \cdot R_{\mathrm{b}}}{K_{\mathrm{p}, \mathrm{h}}}-k_{12} \cdot V_{1} \cdot C_{\mathrm{b}} \\
& \quad+k_{21} X_{\text {peripheral }}-C L_{\mathrm{r}} \cdot C_{\mathrm{b}}
\end{aligned}
$$

where $X_{\mathrm{g}}$ and $X_{\text {peripheral }}$ are the amounts of the chemicals in the gut and peripheral compartments, respectively; $C_{\mathrm{h}}$ and $C_{\mathrm{b}}$ are the hepatic and blood chemical concentrations, respectively; $V_{\mathrm{h}}$ and $V_{1}$ are the volumes of the liver and the central compartment, respectively; $F_{\mathrm{a}}$ and $F_{\mathrm{g}}$ are availability; $k_{12}$ and $k_{21}$ are rate constants; and $Q_{\mathrm{h}}$ is the hepatic blood flow rate of the systemic circulation in the hepatic compartment.

The calculated maximum plasma concentrations and areas under the concentration-time curves (AUC) of 34 diverse chemicals (15) and an updated selection of 70 chemicals (unpublished) obtained using the one-compartment models and our simplified PBPK models were found to be consistent $(r>0.95)$. However, for 53 chemicals as shown in Table
1 (15) [and an updated selection of 70 chemicals (unpublished)], there were only approximate correlations $(r=\sim 0.4-$ $0.6)$ between the hepatic and plasma concentrations and AUC values (15) as estimated using our PBPK model. Moreover, the liver and plasma concentrations of the tested chemicals estimated by the PBPK models differed considerably from the reported empirical values.

Among the compounds with a broad diversity of structures that were used in the PBPK modeling, seven had reported hepatoxicity NOEL or lowest-observed-effect level (LOEL) values in the HESS database (Table 2) (16). The LOEL values in rats for oral administrations of 2-mercaptobenzimidazole (CAS No. 583-39-1), 4-nonylphenol (84852-15-3), paraacetaldehyde (123-63-7), 1,2,3-trimethylbenzene (526-73-8), 1,2,4-trimethylbenzene (95-63-6), $m$-cresol (108-39-4), and bisphenol A (80-05-7) were of the order of $10,250,300,300,300,300$, and $600 \mathrm{mg} / \mathrm{kg} /$ day, respectively. The main PBPK model parameters, namely, absorption rate constants, distribution volumes, and hepatic intrinsic clearance values, for these seven compounds are shown in Table 2. Among the simple PBPK modeling results shown in Table 2 for virtual oral administration of $1.0 \mathrm{mg} / \mathrm{kg}$ to rats, the highest values for the maximum plasma concentration and AUC were observed

Table 1. Names of the chemicals tested in the current PBPK modeling

\begin{tabular}{lllll}
\hline \hline Acetaminophen & Chlorpyrifos & Itopride & Omeprazole & Thalidomide \\
Acrylonitrile & $m$-Cresol & Lenalidomide & Oseltamivir & Tolbutamide \\
Alprazolam & $p$-Cresol & Losartan & Paraacetaldehyde & Toluene \\
Aniline & Dabigatran & Melengestrol acetate & Pemafibrate & Trichloroethylene \\
Apixaban & Dextromethorphan & 2-Mercaptobenzimidazole & PF-04937319 & Trimethylamine \\
Apomorphine & Dichlorodiphenyltrichloroethane & Metoprolol & Pomalidomide & 1,2,3-Trimethylbenzene \\
Atomoxetine & Dichloromethane & Midazolam & Rivaroxaban & 1,2,4-Trimethylbenzene \\
Azithromycin & 1,4-Dioxane & Molinate & Styrene & Verapamil \\
Benzydamine & Disopyramide & Mono(2-ethylhexyl) phthalate & Tetrabromobisphenol A & Warfarin \\
Bisphenol A & Edoxaban & Nicotine & 2,3,5,6-Tetrafluorobenzylalcohol & \\
Caffeine & Fluvoxamine & 4-Nonylphenol & Tetramethylammonium & \\
\hline
\end{tabular}

\begin{tabular}{|c|c|c|c|c|c|c|c|c|c|c|c|}
\hline \multirow[b]{2}{*}{ Substrate } & \multirow[b]{2}{*}{ CAS No. } & \multirow[b]{2}{*}{$\log P_{\text {app }}$} & \multicolumn{3}{|c|}{ PBPK parameters } & \multicolumn{4}{|c|}{ PBPK modeling results } & \multirow{2}{*}{\multicolumn{2}{|c|}{$\frac{\text { NOEL LOEL }}{\mathrm{mg} / \mathrm{kg} / \text { day }}$}} \\
\hline & & & $\begin{array}{l}k_{\mathrm{a}} \\
1 / \mathrm{h}\end{array}$ & $\begin{array}{l}V_{1}, \\
\mathrm{~L}\end{array}$ & $\begin{array}{c}C L_{\mathrm{h}, \mathrm{in}}, \\
\mathrm{L} / \mathrm{h}\end{array}$ & $\begin{array}{c}C_{\max }, \\
\mathrm{ng} / \mathrm{mL}\end{array}$ & $\begin{array}{c}\text { AUC, } \\
\text { ng h/mL }\end{array}$ & $\begin{array}{c}\text { Liver } \mathrm{C}_{\max }, \\
\mathrm{ng} / \mathrm{g}\end{array}$ & $\begin{array}{l}\text { Liver AUC, } \\
\text { ng h/g }\end{array}$ & & \\
\hline 2-Mercaptobenzimidazole & $583-39-1$ & 2.8 & 1.9 & 1.6 & 0.1 & 172 & 2500 & 2550 & 11600 & 2 & 10 \\
\hline 4-Nonylphenol & $84852-15-3$ & NA & 1.4 & 1.2 & 48.4 & 203 & 1350 & 2440 & 6570 & 15 & 250 \\
\hline Paraacetaldehyde & $123-63-7$ & NA & 2.9 & 0.2 & 0.1 & 1070 & 7930 & 840 & 5960 & 100 & 300 \\
\hline 1,2,3-Trimethylbenzene & $526-73-8$ & NA & 1.4 & 1.6 & 7.3 & 30 & 180 & 630 & 1130 & 30 & 300 \\
\hline 1,2,4-Trimethylbenzene & $95-63-6$ & NA & 1.5 & 1.7 & 7.6 & 29 & 175 & 683 & 1110 & 100 & 300 \\
\hline$m$-Cresol & $108-39-4$ & 2.9 & 2.9 & 0.1 & 2.0 & 459 & 421 & 913 & 668 & 100 & 300 \\
\hline Bisphenol A & $80-05-7$ & 2.5 & 3.5 & 2.6 & 62.4 & 15 & 66 & 1070 & 373 & 200 & 600 \\
\hline
\end{tabular}

These chemicals are those examined in our previous report (15).

Table 2. PBPK parameters and modeling results of seven compounds after virtual oral administration $(1.0 \mathrm{mg} / \mathrm{kg})$ and their reported hepatic NOEL and LOEL values in rats

$\mathrm{NA}$, not available. Data were obtained from our previous report (15). 
for paraacetaldehyde $(1,070 \mathrm{ng} / \mathrm{mL}$ and $7,930 \mathrm{ng} \mathrm{h} / \mathrm{mL}$, respectively). In contrast, the highest values for the maximum concentration and AUC in the livers were seen with 2-mercaptobenzimidazole $(2,550 \mathrm{ng} / \mathrm{mL}$ and $11,600 \mathrm{ng} \mathrm{h} /$ $\mathrm{mL}$, respectively), which also had the lowest hepatic LOEL value in this group. Further analysis showed that the LOEL values given in the HESS database and the hepatic AUC values that we obtained from the PBPK modeling were inversely correlated $(r=-0.78, p<0.05, \mathrm{n}=7)$. This significant example indicated the importance of simulating the hepatic levels of general chemicals because those with high hepatic concentrations are more likely to be potent hepatotoxic compounds.

\section{CONCLUSION AND FUTURE STUDY}

In this review, the broad chemical diversity of the substances tested is illustrated in a two-dimensional plane depicting the chemical space (Fig. 2). We determined the permeability across the intestinal epithelial cell monolayers (in a pH-dependent Caco-2 cell system) of a diverse range of industrial chemicals/drugs. These permeability values provided a good estimation of oral absorbance as a putative marker of hepatotoxicity. Further analysis revealed that the cell permeability coefficients of the industrial chemicals were inversely correlated to their hepatic NOELs (Fig. 3), suggesting that the estimation of oral absorbance could be a useful tool to indicate hepatotoxicity in vivo. Moreover, the hepatic LOELs of chemicals and the virtual hepatic AUCs derived using PBPK modeling were also inversely correlated (Table 2). Therefore, using PBPK models to estimate hepatic chemical concentrations following oral administration could also be useful as an indicator of hepatotoxicity in vivo. The present simplified PBPK models could estimate the relationships between hepatic/plasma concentrations of chemicals and their oral doses using both forward and reverse dosimetry and provide a useful approach to predict hepatotoxicity. Estimation of the parameters for simplified PBPK modeling (Fig. 4B) of additional chemicals will be carried out in future research projects by our research group. To develop a more precise hepatotoxicity prediction system based on PBPK modeling, it would be valuable to establish supportive equations to predict the key parameters for this simple PBPK modeling approach. In future, in-depth forward and reverse dosimetry assessments of industrial chemical levels would be facilitated by adopting more human PBPK models $(9,32)$ based on the above-described animal PBPK modeling techniques. In conclusion, evaluation of chemical exposure levels in the liver after oral doses should be one of the key primary steps, and mechanistic metabolic activations and their modifications (33) will be critical to understanding the potential risk from multiple exposures (34) in the field of chemical toxicology.

\section{ACKNOWLEDGMENTS}

We thank Drs. Kimito Funatsu and Fumiaki Shono (Tokyo University) for chemical space diversity evaluation and their general support and Drs. Makiko Shimizu and Norie Murayama (Showa Pharmaceutical University) for their collaboration in our laboratory. We also thank David Smallbones for copyediting a draft of this article. This original work was supported by the Ministry of Economy and Trade Industry (METI) Artificial Intelligence-based Substance Hazard Integrated Prediction System Project (AI-SHIPS project), Japan.

\section{CONFLICT OF INTEREST}

There is no conflict of interest.

Received July 23, 2019; Revised August 12, 2019; Accepted August 26, 2019

\section{REFERENCES}

1. Alwis, K.U., Blount, B.C., Britt, A.S., Patel, D. and Ashley, D.L. (2012) Simultaneous analysis of 28 urinary VOC metabolites using ultra high performance liquid chromatography coupled with electrospray ionization tandem mass spectrometry (UPLC-ESI/MSMS). Anal. Chim. Acta, 750, 152-160.

2. Sexton, K., Adgate, J.L., Fredrickson, A.L., Ryan, A.D., Needham, L.L. and Ashley, D.L. (2006) Using biologic markers in blood to assess exposure to multiple environmental chemicals for inner-city children 3-6 years of age. Environ. Health Persp., 114, 453-459.

3. Bell, S.M., Chang, X., Wambaugh, J.F., Allen, D.G., Bartels, M., Brouwer, K.L.R., Casey, W.M., Choksi, N., Ferguson, S.S., Fraczkiewicz, G., Jarabek, A.M., Ke, A., Lumen, A., Lynn, S.G., Paini, A., Price, P.S., Ring, C., Simon, T.W., Sipes, N.S., Sprankle, C.S., Strickland, J., Troutman, J., Wetmore, B.A. and Kleinstreuer, N.C. (2018) In vitro to in vivo extrapolation for high throughput prioritization and decision making. Toxicol. In Vitro, 47, 213-227.

4. Rotroff, D.M., Wetmore, B.A., Dix, D.J., Ferguson, S.S., Clewell, H.J., Houck, K.A., LeCluyse, E.L., Andersen, M.E., Judson, R.S., Smith, C.M., Sochaski, M.A., Kavlock, R.J., Boellmann, F., Martin, M.T., Reif, D.M., Wambaugh, J.F. and Thomas, R.S. (2010) Incorporating human dosimetry and exposure into high-throughput in vitro toxicity screening. Toxicol. Sci., 117, 348-358.

5. Wetmore, B.A., Wambaugh, J.F., Ferguson, S.S., Sochaski, M.A., Rotroff, D.M., Freeman, K., Clewell, H.J., III, Dix, D.J., Andersen, M.E., Houck, K.A., Allen, B., Judson, R.S., Singh, R., Kavlock, R.J., Richard, A.M. and Thomas, R.S. (2012) Integration of dosimetry, exposure, and high-throughput screening data in chemical toxicity assessment. Toxicol. Sci., 125, 157-174.

6. Wambaugh, J.F., Wetmore, B.A., Pearce, R., Strope, C., Goldsmith, R., Sluka, J.P., Sedykh, A., Tropsha, A., Bosgra, 
S., Shah, I., Judson, R., Thomas, R.S. and Setzer, R.W. (2015) Toxicokinetic triage for environmental chemicals. Toxicol. Sci., 147, 55-67.

7. Wambaugh, J.F., Hughes, M.F., Ring, C.L., MacMillan, D.K., Ford, J., Fennell, T.R., Black, S.R., Snyder, R.W., Sipes, N.S., Wetmore, B., Westerhout, J., Setzer, R.W., Pearce, R., Simmons, J.E. and Thomas, R.S. (2018) Evaluating in vitro-in vivo extrapolation of toxicokinetics. Toxicol. Sci., 63, 152-169.

8. Takano, R., Murayama, N., Horiuchi, K., Kitajima, M., Kumamoto, M., Shono, F. and Yamazaki, H. (2010) Blood concentrations of acrylonitrile in humans after oral administration extrapolated from in vivo rat pharmacokinetics, in vitro human metabolism, and physiologically based pharmacokinetic modeling. Regul. Toxicol. Pharmacol., 58, 252258.

9. Yamazaki, H., Suemizu, H., Mitsui, M., Shimizu, M. and Guengerich, F.P. (2016) Combining chimeric mice with humanized liver, mass spectrometry, and physiologicallybased pharmacokinetic modeling in toxicology. Chem. Res. Toxicol., 29, 1903-1911.

10. Yamashita, S., Tanaka, Y., Endoh, Y., Taki, Y., Sakane, T., Nadai, T. andSezaki, H. (1997) Analysis of drug permeation across Caco-2 monolayer: implication for predicting in vivo drug absorption. Pharm. Res., 14, 486-491.

11. Hilgers, A.R., Conradi, R.A. and Burton, P.S. (1990) Caco-2 cell monolayers as a model for drug transport across the intestinal mucosa. Pharm. Res., 7, 902-910.

12. Leonard, M., Creed, E., Brayden, D. and Baird, A.W. (2000) Iontophoresis-enhanced absorptive flux of polar molecules across intestinal tissue in vitro. Pharm. Res., 17, 476-478.

13. Artursson, P., Palm, K. and Luthman, K. (2001) Caco-2 monolayers in experimental and theoretical predictions of drug transport. Adv. Drug Deliv. Rev., 46, 27-43.

14. Neuhoff, S., Ungell, A.L., Zamora, I. andArtursson, P. (2005) pH-Dependent passive and active transport of acidic drugs across Caco-2 cell monolayers. Eur. J. Pharm. Sci., 25, 211-220.

15. Kamiya, Y., Otsuka, S., Miura, T., Takaku, H., Yamada, R., Nakazato, M., Nakamura, H., Mizuno, S., Shono, F., Funatsu, K. and Yamazaki, H. (2019) Plasma and hepatic concentrations of chemicals after virtual oral administrations extrapolated using rat plasma data and simple physiologically based pharmacokinetic models. Chem. Res. Toxicol., 32, 211-218.

16. Sakuratani, Y., Zhang, H.Q., Nishikawa, S., Yamazaki, K., Yamada, T., Yamada, J., Gerova, K., Chankov, G., Mekenyan, O. and Hayashi, M. (2013) Hazard Evaluation Support System (HESS) for predicting repeated dose toxicity using toxicological categories. SAR QSAR. Environ. Res., 24, 351363.

17. Adachi, K., Suemizu, H., Murayama, N., Shimizu, M. and Yamazaki, H. (2015) Human biofluid concentrations of mono(2-ethylhexyl)phthalate extrapolated from pharmacokinetics in chimeric mice with humanized liver administered with di(2-ethylhexyl)phthalate and physiologically based pharmacokinetic modeling. Environ. Toxicol. Pharmacol., 39, 1067-1073.

18. Miura, T., Uehara, S., Nakazato, M., Kusama, T., Toda, A., Kamiya, Y., Murayama, N., Shimizu, M., Suemizu, H. and
Yamazaki, H. (2019) Human plasma and liver concentrations of styrene estimated by combining a simple physiologically based pharmacokinetic model with rodent data. $J$. Toxicol. Sci., 44, 543-548.

19. Miura, T., Suemizu, H., Goto, M., Sakai, N., Iwata, H., Shimizu, M. and Yamazaki, H. (2019) Human urinary concentrations of monoisononyl phthalate estimated using physiologically based pharmacokinetic modeling and experimental pharmacokinetics in humanized-liver mice orally administered with diisononyl phthalate. Xenobiotica, 49, 513-520.

20. Miura, T., Uehara, S., Mizuno, S., Yoshizawa, M., Murayama, N., Kamiya, Y., Shimizu, M., Suemizu, H. and Yamazaki, H. (2019) Steady-state human pharmacokinetics of monobutyl phthalate predicted by physiologically based pharmacokinetic modeling using single-dose data from humanized-liver mice orally administered with dibutyl phthalate. Chem. Res. Toxicol., 32, 333-340.

21. Miyaguchi, T., Suemizu, H., Shimizu, M., Shida, S., Nishiyama, S., Takano, R., Murayama, N. and Yamazaki, H. (2015) Human urine and plasma concentrations of bisphenol A extrapolated from pharmacokinetics established in in vivo experiments with chimeric mice with humanized liver and semi-physiological pharmacokinetic modeling. Regul. Toxicol. Pharmacol., 72, 71-76.

22. Shimizu, M. and Yamazaki, H. (2017) Human plasma and urinary metabolic profiles of trimethylamine and trimethylamine N-oxide extrapolated using a simple physiologically based pharmacokinetic model. J. Toxicol. Sci.,42, 485-490.

23. Shimizu, M., Suemizu, H., Mizuno, S., Kusama, T., Miura, T., Uehara, S. and Yamazaki, H. (2018) Human plasma concentrations of trimethylamine N-oxide extrapolated using pharmacokinetic modeling based on metabolic profiles of deuterium-labeled trimethylamine in humanized-liver mice. J. Toxicol. Sci., 43, 387-393.

24. Takano, R., Murayama, N., Horiuchi, K., Kitajima, M., Shono, F. and Yamazaki, H. (2010) Blood concentrations of 1,4-dioxane in humans after oral administration extrapolated from in vivo rat pharmacokinetics, in vitro human metabolism, and physiologically based pharmacokinetic modeling. J. Health Sci., 56, 557-565.

25. Tsukada, A., Suemizu, H., Murayama, N., Takano, R., Shimizu, M., Nakamura, M. and Yamazaki, H. (2013) Plasma concentrations of melengestrol acetate in humans extrapolated from the pharmacokinetics established in in vivo experiments with rats and chimeric mice with humanized liver and physiologically based pharmacokinetic modeling. Regul. Toxicol. Pharmacol., 65, 316-324.

26. Yamashita, M., Suemizu, H., Murayama, N., Nishiyama, S., Shimizu, M. and Yamazaki, H. (2014) Human plasma concentrations of herbicidal carbamate molinate extrapolated from the pharmacokinetics established in in vivo experiments with chimeric mice with humanized liver and physiologically based pharmacokinetic modeling. Regul. Toxicol. Pharmacol., 70, 214-221.

27. Yamazaki, H., Horiuchi, K., Takano, R., Nagano, T., Shimizu, M., Kitajima, M., Murayama, N. and Shono, F. (2010) Human blood concentrations of cotinine, a biomonitoring marker for tobacco smoke, extrapolated from nicotine metabolism in rats and humans and physiologically based 
pharmacokinetic modeling. Int. J. Environ. Res. Public Health, 7, 3406-3421.

28. Yamazaki, H., Takano, R., Horiuchi, K., Shimizu, M., Murayama, N., Kitajima, M. and Shono, F. (2010) Human blood concentrations of dichlorodiphenyltrichloroethane (DDT) extrapolated from metabolism in rats and humans and physiologically based pharmacokinetic modeling. $J$. Health Sci., 56, 566-575.

29. Emoto, C., Murayama, N., Rostami-Hodjegan, A. and Yamazaki, H. (2009) Utilization of estimated physicochemical properties as an integrated part of predicting hepatic clearance in the early drug-discovery stage: Impact of plasma and microsomal binding. Xenobiotica, 39, 227-235.

30. Poulin, P. and Theil, F.P. (2002) Prediction of pharmacokinetics prior to in vivo studies. 1. Mechanism-based prediction of volume of distribution. J. Pharm. Sci., 91, 129-156.
31. Kato, M., Shitara, Y., Sato, H., Yoshisue, K., Hirano, M., Ikeda, T. and Sugiyama, Y. (2008) The quantitative prediction of CYP-mediated drug interaction by physiologically based pharmacokinetic modeling. Pharm. Res., 25, 18911901.

32. Yamazaki, H. (2017) Differences in toxicological and pharmacological responses mediated by polymorphic cytochromes P450 and related drug-metabolizing enzymes. Chem. Res. Toxicol., 30, 53-60.

33. Shimada, T. (2017) Inhibition of carcinogen-activating cytochrome P450 enzymes by xenobiotic chemicals in relation to antimutagenicity and anticarcinogenicity. Toxicol. Res. 33, 79-96.

34. Nohmi, T. (2018) Thresholds of genotoxic and non-genotoxic carcinogens. Toxicol. Res., 34, 281-90. 